\title{
Corporate Social Responsibility and the Right to Employment of Persons with Disabilities
}

\author{
Marco Fasciglione
}

\section{Introduction}

Access to employment is recognized as a fundamental human right in the United Nations Convention on the Rights of Persons with Disabilities (hereinafter CRPD). However, and as far as the European Union, which is a Party of CRPD, the proportion of persons with disabilities not participating in the labour market is at least twice as high as that of average EU citizens. ${ }^{1}$ This situation increases their poverty risk that social benefits cannot compensate, especially in presence of severe economic crisis impairing the allocation of resources for public expenditures in welfare field area.

The adoption of the CRPD in 2006 has further strengthened the social model of disability and granted persons with disabilities with a wide spectrum of human rights including the right to employment based on the principles of equal treatment, accessibility and non-discrimination. Employment is considered one of the pivotal elements of social inclusion, that is especially important for the employment of persons with disabilities in the mainstream labour market. However, the official unemployment rates for persons with disabilities of working age in most of the developed countries are still reported at least twice low than for those with no disability. Since persons with disabilities are pronounced to be equal members of society by international institutions and are recognized as an important group of human diversity who have rights including the right to employment, their integration into employment sphere has been progressively included within the CSR

\footnotetext{
${ }^{1}$ See Grammenos (2011), p. 22.

M. Fasciglione ( $\square)$

Institute for International Legal Studies (ISGI-CNR), Naples, Italy

e-mail: marco.fasciglione@cnr.it 
policy agenda at international ${ }^{2}$ and at regional level ${ }^{3}$ recognizing disability as a relevant item in CSR agendas. Nowadays, hiring persons with disabilities is increasingly recognized as a part of the philosophy of corporate social responsibility (CSR) and an essential dimension of the workforce diversity.

\section{The Shift from the Medical Model to the Social Model of Disability and Its Impact on the Perception of the Role of Private Sector's Entities}

At the international level, there has been significant evolution in the approach to persons with disability. ${ }^{4}$ Historically, persons with disability have been treated as objects of pity and as burdens on their families and societies. According to this view, disability would be a 'personal tragedy' and persons with disability would be victims of great misfortune and perceived as socially dead or better off dead, as passively coming to terms with a condition that will forever limit their activities. According to this perspective the focus is on the 'affliction' caused by the particular condition or impairment and the provision of cure, treatment, care and protection to change the person so that they may be assimilated to the social norm. This is commonly referred to as the medical model of disability, which has probably been the most powerful influence on the conceptualisation of disability in modern history ${ }^{5}$ and '... has guided and dominated clinical practice with the resulting assumption that both problems and solutions lie within people with disabilities rather than within society'. 6 This perception of disability not only has reinforced the idea that it is the impairment itself that causes the limitation, without recognising the role of the social environment in disabling persons with impairments, but has also influenced policy responses to persons with impairments, resulting in a disabling culture that perpetuates negative attitudes and discriminatory practices that ultimately oppress and exclude persons with impairments.

\footnotetext{
${ }^{2}$ See principle 6 of UN Global Compact concerning the elimination of discrimination in respect of employment and occupation, available at http://www.unglobalcompact.org. For all websites, last access 30 October 2014.

${ }^{3}$ See the European Commission's new Communication, A renewed EU strategy 2011-2014 for Corporate Social Responsibility (COM(2011) 681 final, 25.10.2011), pp. 10 and 14.

${ }^{4}$ As far as the evolutions of approached and policies dealing with disability, see, among the others, Shakespeare (2006), Bickenbach (1999), and Oliver (1996).

${ }^{5}$ The medical model views disability as a deficiency or deviation from the norm, located in the individual, and carries an action implication to treat or change the person so that they can conform to existing social processes and structures. This treatment is typically provided in service systems and settings isolated from the general community. The medical model is not confined to the health domain, but for many persons with disability, has pervaded all areas of life. Examples include institutional residential services, special education systems and sheltered employment.

${ }^{6}$ French (1994), p. 4.
} 
On the contrary, the social model of disability ${ }^{7}$ locates the experience of disability in the social environment, rather than in the impairment, and carries with it the inference that problems of disability have to be located squarely within society by noting that it is not individual limitations which are the cause of the problem but society's failure to provide appropriate services and adequately ensure the needs of persons with disabilities are fully taken into account in its social organisation. This model involved disability activist academics reinterpreting 'disability' as social oppression, ${ }^{8}$ and radically refocusing the agenda away from cure, treatment, care and protection to acceptance of impairment as a positive dimension of human diversity, and to the problematisation and rejection of a social norm that results in exclusion. The social model has had an enormous influence in the development of the CRPD and is continuing to evolve; furthermore this shift of paradigms has contributed in highlighting the role played by all the actors of society in preventing and fighting discrimination against person with disability, included business entities. From this perspective, the focus on the contribution of the private sector has matched the emerging debates at international level as to the responsibility for human rights of private sector entities and on the challenges posed to the full and effective realization of human rights by their activities.

\section{The Rise of the Role of Business Actors Within Human Rights Protection Field Area}

International human rights treaties generally do not impose direct legal obligations on business enterprises. Legal liability and enforcement for the infringement by businesses of international human rights standards are, therefore, defined largely by national law. ${ }^{9}$ However, in the last decades the demand that business sector demonstrate a commitment to conducing its operations in a manner that takes into account of human rights of individuals that might be impaired by these operations and of the level of vulnerability of workers, has increased. The rising of public concerns as to the need for constraints on corporate conducts for human rights protection purposes, have become more pronounced with the current wave of globalization, expansion in international trade, and explosive growth in certain developing countries in the areas of manufacturing, mining, oil and gas, forestry, etc. Also well-established is the circumstance that according to international legal system on human rights, States bear the legal obligation to respect, protect and fulfil

\footnotetext{
${ }^{7}$ The social model of disability is a generic term for a broad theory of disability that began to emerge from the mid 1960s principally from within the disability rights movement in the United Kingdom.

${ }^{8}$ See Quinn (1999), p. 281.

${ }^{9}$ As to the literature on general human rights see Cushman (2012), Rehman (2010), Hunt (2007), and Ishay (2008).
} 
the human rights set out in the international human rights conventions they ratify. ${ }^{10}$ More in particular, the obligation of States to respect human rights means that they must refrain from interfering with or curtailing the enjoyment of human rights. Their obligation to protect human rights requires them to protect individuals and groups against human rights abuses, including by business enterprises. Their obligation to fulfil human rights means that States must take positive action to facilitate the enjoyment of basic human rights. As far as the obligation to protect, nowadays is well-established in international human rights law the duty of States to protect against non-State human rights abuses within their jurisdiction. This duty not only extends to the protection against abuses by business entities; also, it has been included within the core United Nations human rights treaties as elaborated by the treaty bodies, and is also generally agreed to exist under customary international law. What is interesting is the fact that treaty bodies unanimously affirm that this duty requires steps by States to regulate and adjudicate abuses by all social actors including businesses. However, the earlier United Nations human rights treaties, such as the International Convention on the Elimination of All Forms of Racial Discrimination (ICERD), the International Covenant on Economic, Social and Cultural Rights (ICESCR), and the International Covenant on Civil and Political Rights (ICCPR), do not specifically address State duties regarding business. They impose, on the contrary, generalized obligations to ensure the enjoyment of rights and prevent non-State abuse. For examples, ICERD requires each State party to prohibit racial discrimination by 'any persons, group or organization' (Article 2.1 (d)). And some of the treaties recognize rights that are particularly relevant in business contexts, including rights related to employment, health and indigenous communities.

What is worth noting, here, is the circumstance that these treaties, generally, in conceding to States discretion regarding the modalities for regulating and adjudicating non-State abuses, emphasize legislation and judicial remedies. Furthermore, the treaty bodies monitoring fair enforcement of these international conventions, have widely elaborated upon the duty to protect. General Comment No. 31 of the Human Rights Committee (HRC) may be seen as confirming the paradigm of such approach. According to the General Comment, indeed, under the ICCPR 'the positive obligations on States parties to ensure Covenant rights will only be fully discharged if individuals are protected by the State, not just only against violations of Covenant rights by its agents, but also against acts committed by private persons or entities'. ${ }^{11}$ The General Comment further clarifies that States could breach Covenant obligations where they permit or fail 'to take appropriate measures or

\footnotetext{
${ }^{10}$ As far as the tripartite division see Eide (1984). A fourth level partition (obligations of respect, protect, ensure and promote) has been proposed by Van Hoof (1984). More recently, a scheme consisting of five levels of obligations (respect rights of others; create institutional machinery essential to realization of rights, protect rights/prevent violations; provide good ad services to satisfy rights; promote rights) has been proposed by Alston and Steiner (2000).

${ }^{11}$ HRC, General Comment No. 31, Nature of the General Legal Obligation on States Parties to the Covenant, U.N. Doc. CCPR/C/21/Rev.1/Add.13 (2004), para 8.
} 
to exercise due diligence to prevent, punish, investigate or redress the harm caused by such acts by private persons or entities'. Therefore, the case-law of all main human rights treaty bodies has started to express concern about State failures to protect against business abuse most frequently in relation to the right to nondiscrimination, indigenous peoples' rights, and labour and health-related rights. This duty to protect applies to all substantive rights and the monitoring bodies tend not to specify the precise content of required State action, but generally recommend regulation through legislation and adjudication through judicial remedies, including compensation where appropriate. An identical evolution may be perceived at regional human rights systems; also regional mechanisms, in effect, have recognized the State duty to protect against non-State abuse, and established similar correlative State requirements to regulate and adjudicate corporate acts. ${ }^{12}$

In sum, the State duty to protect against non-State abuses is part of the very foundation of the international human rights regime: this duty requires States to play a key role in regulating and adjudicating also abuses by business enterprises risking to breach their international obligations.

\section{The State Duty to Protect from Private Actors' Violations of the CRPD in the Employment Field Area}

The duty on States to protect individuals from infringements occurring within the framework of business operations is also at the heart of the CRPD system and hence applies, as far as Article 27 of the Convention, to private sector employers. According to the Convention States parties bear the general obligation to promote, protect and ensure the full and equal enjoyment of all human rights and fundamental freedoms by all persons with disabilities and to promote respect for their inherent dignity. As far as the duty to protect the rights of persons with disability within the employment field area, Article 5 of the Convention obliges State Parties to prohibit all discrimination on the basis of disability and guarantee to persons with disabilities equal and effective legal protection against discrimination on all grounds. Furthermore, in order to promote equality and eliminate discrimination, States Parties are requested to take all appropriate steps to ensure that reasonable accommodation is provided. Finally, under Article 27 of the Convention, which recognizes the right of persons with disabilities to work on an equal basis with others in work freely chosen and in a work environment that is open, inclusive and accessible, State parties are bound to safeguard and promote the realization of the right to work for such category of individuals by taking appropriate steps including legislation. From this perspective member States are expected, if necessary, to review and amend their domestic workplace laws and policies in order to prohibit

\footnotetext{
${ }^{12}$ For an overview of regional human rights mechanism approach see Clapham (2006) and Udombana (2004).
} 
discrimination, protect rights, promote the employment in the private sector through policies and measures such as affirmative action, incentives, etc.

The right of persons with disabilities to employment involves, therefore, an obligation on States parties to create an enabling and conducive environment for employment, in both the public and private sectors. Accordingly, Article 27 of the Convention guides States parties in the implementation of such right by setting forth some basic rules: (a) non-discrimination, as the persons with disabilities have the right to work on an equal basis with others; (b) accessibility, as the right of persons with disabilities to work includes the opportunity to gain a living in a work environment that is accessible to persons with disabilities, identifying and removing barriers that hinder persons with disabilities from carrying out their work on an equal basis with others; (c) reasonable accommodation, as with a view to facilitating access of persons with disabilities to work on an equal basis with others, States parties must ensure that reasonable accommodation is provided to persons with disabilities who request it, and should take effective steps, including through legislation, to ensure that the denial of reasonable accommodation constitutes discrimination; (d) besides a duty to impose obligations on private-sector employers, States should adopt positive measures to promote employment opportunities for persons with disabilities.

These standards, therefore, impose different levels of obligations on States; more in particular according to a first perspective, State are obliged to abstain from infringing rights of persons with disabilities; from a second perspective the Convention fixes a duty to protect rights of persons with disability stemming from Article 27. In achieving this goal States bear several positive obligations including the duty to promote employment opportunities for persons with disabilities and this especially with regard to private-sector employers. ${ }^{13}$ Amongst the implementation measures that States parties should take on the basis of the Convention, a pivotal role is played by the duty of aligning national standards and practice to the Convention. In this respect, Article 4, para 1 (a) and (b) of the Convention imposes

\footnotetext{
${ }^{13}$ There are several examples of government-driven initiatives enforcing such State duty. In Belgium the Federal Government developed in 2005, in cooperation with the regions, a new Equality-Diversity label for enterprises in respect of employment and promotion of diversity. In 2006, a pilot project was launched, with the enterprises concerned making an active commitment to further diversity and equality within their organizations in order to obtain the label. So far, 15 of the enterprises involved in the project have been awarded the label. As far as Germany is concerned, the 'Diversity Charter', a corporate initiative under the patronage of Federal Chancellor Angela Merkel, launched in 2006, seeks to create a corporate culture that is typified by fairness and respect. The signatories undertake to create a working environment which is free of prejudices and marginalisation in which each worker experiences respect, regardless of gender, race, nationality, ethnic origin, religion or philosophical creed, disability, age, sexual orientation and identity. More than 900 enterprises and public facilities all over Germany have so far subscribed to the Charter. In Luxemburg the 2003 law relative aux personnes handicapées of 12 September 2003 and successive amendments has introduced the 'disability management' approach, a qualified form of case-management pursuing the goal of support job retention of employees who due to a decrease in their ability to work may become inactive.
} 
two general obligations on States parties; namely: (a) to adopt all appropriate legislative, administrative and other measures for the implementation of the rights recognized in the Convention related to work and employment, and (b) to take all appropriate measures, including legislation, to modify or abolish laws, regulations, customs and practices that constitute discrimination against persons with disabilities in the areas of work and employment.

\section{From the State Duty to Protect to the Corporate Duty to Respect: Corporate Social Responsibility Standards and Disability}

Internationally recognized CSR standards and guidelines addressing disability, usually focus their attention on the principles of non-discrimination and equality. As for instance, the latest 2011 amendments to these OECD Guidelines (2011) - the fifth since 1976-require that enterprises comply with the principles of non-discrimination and respect the human rights of specific categories of individuals, including persons with disabilities. The Guidelines address enterprises to recruit persons with disabilities from local communities and invest in their training and lifelong learning.

At the United Nations level, the Global Compact launched in 1999, involves corporations from all over the world to voluntary advance ten principles that address human rights, labour, the environment, and anti-corruption policies. ${ }^{14}$ According to principle 6 of the Compact, 'businesses should uphold the elimination of discrimination in respect of employment and occupation'. With this aim, discrimination in employment and occupation has to be interpreted in the sense of treating people differently or less favourably because of characteristics that are not related to their merit or the inherent requirements of the job. In international and national law, these characteristics commonly include: race, colour, sex, religion, political opinion, national extraction, social origin, age, disability, HIV/AIDS status, trade union membership, and sexual orientation; however, Principle 6 allows companies to consider additional grounds where discrimination in employment and occupation may occur. The different forms of discrimination can arise in a variety of work-related activities, including access to employment, to particular occupations, promotions and to training and vocational guidance. Moreover, discrimination can occur with respect to the terms and conditions of the employment, such as: recruitment, remuneration, hours of work and rest/paid holidays, maternity protection, security of tenure, job assignments, performance assessment and advancement, training and opportunities, job prospects, social security, occupational safety and health. For example, the UN Global Compact, hailed as 'the world's largest corporate citizenship and sustainability initiative', has an existing membership of

${ }^{14}$ As to the Global Compact see Rasche and Kell (2010). 
only 8,000 participants, with approximately 6,000 being businesses situated across 135 countries. While these numbers may appear impressive at first glance, even the UN Secretary-General has labelled the initiative's current participation rate inadequate, insofar as it reflects only a small percentage of the estimated 70,000 multinationals and millions of small businesses. Moreover, already more than 2,400 companies have faced expulsion from the Global Compact's esteemed membership 'for failing to report to their stakeholders on [human rights-related] progress they have made'. 15

The idea that business has to play a more prominent societal role also occupies an important part of the European Union's debates on Union policy developments. The Green Paper of the European Commission of 2001 articulates the importance of going beyond compliance to legislation and investing into human capital, environment and stakeholders such as business partners and suppliers, customers, public authorities and local communities organizations. ${ }^{16}$ In the 2002 follow up document, the European Commission pronounces such aspects of CSR as provision of quality employment, lifelong learning and equal opportunities and considers integration of persons with disabilities an important aspect to be addressed by CSR strategies. In this respect, enterprises are encouraged to exchange CSR experiences and to act in a socially responsible manner towards people with disabilities in relation to promoting equal employment opportunities, developing designed-for-all products and improving accessibility to assistive technologies. ${ }^{17}$ The recently 2011 Communication of the Commission setting forth a renewed EU strategy 2011-2014 for CSR, articulates hiring persons with disabilities an important social responsibility issue recognized as a part of the business CSR philosophy. ${ }^{18}$

\section{The Corporate Duty to Respect: The 2011 United Nations Guiding Principles on Business and Human Rights and the 'Protect, Respect and Remedy' Framework}

The work of Professor John Ruggie, appointed in 2005 as the Special Representative of the UN Secretary-General (hereinafter, SRSG) on the issue of human rights and transnational corporations and other business enterprises, represents a

\footnotetext{
${ }^{15}$ UN Global compact, Secretary-General Urges Companies to Join Global Compact, available at http://www.unglobalcompact.org/news/134-06-21-2011.

${ }^{16}$ See European Commission Green Paper: Promoting a European Framework for Corporate Social Responsibility. Brussels, 18.7.2001.

${ }^{17}$ See European Commission Communication from the Commission Concerning Corporate Social Responsibility: A business contribution to Sustainable Development COM(2002) 347 final Brussels, 2.7.2002.

${ }^{18}$ See European Commission Communication from the Commission A renewed EU strategy 2011-2014 for Corporate Social Responsibility COM(2011) 681 final Brussels, 25.10.2011.
} 
milestone as to the relevance of business in the advancement of human rights and, obviously, it has great relevance as far as the enforcement of CRPD's Article 27 right to employment of persons with disability by corporate actors. It is wellknow that the SRSG work has been crystallized in the 2011 Guiding Principle on Business and Human Rights ${ }^{19}$ which sets out guiding principles for addressing the relationship between business and human rights. The justification for this focus flows from the fact that Ruggie's effort, encompassing a lengthy and inclusive consultation process, has garnered UN endorsement and therefore stands as the most internationally authoritative statement in this area.

The Guiding Principles are the product of 6 years of research commissioned by former UN Secretary General Annan in July 2005. In June 2008, Professor Ruggie presented a report titled 'Protect, Respect and Remedy: a Framework for Business and Human Rights to the UN Human Rights Council' (the 'Framework'). The Framework consists of three core principles: (1) the duty of States to protect against human rights abuses by third parties, including business enterprises; (2) the corporate responsibility to respect human rights; and (3) the need for greater access by victims to effective judicial and non-judicial remedies. The UN Human Rights Council welcomed the Framework and requested that Professor Ruggie offer 'concrete and practical recommendations' for its implementation. In November 2010, Professor Ruggie responded by issuing a draft of the 'Guiding Principles on Business and Human Rights' ('Draft Principles'). The Draft Principles were open for comment for 3 months and received approximately 90 submissions from the business community, NGOs, international organizations, academics, and governments. After considering these written submissions and engaging in consultations with various stakeholders, Professor Ruggie submitted the revised and final text of the Guiding Principles to the Human Rights Council in March 2011, endorsed on 16 July 2011 by Human Rights Council with a specific resolution. ${ }^{20}$

The Guiding Principles do not aspire to create binding international law or impose obligations on TNCs. Rather, its 'normative contribution lies ... in elaborating the implications of existing standards and practices for States and businesses; integrating them within a single, logically coherent and comprehensive template; and identifying where the current regime falls short and how it should be improved' ${ }^{21}$ They, also, do not aim to offer a plug-and-play tool kit for identifying corporate human rights responsibilities. On the contrary, the Principles offer a sliding-scale approach for corporate actors, based on their size and, ostensibly, their location. In the words of the SRSG 'when it comes to means for implementation ... one size does not fit all'. ${ }^{22}$

\footnotetext{
${ }^{19}$ Special Representative of the Secretary-General on the Issue of Human Rights and Transnational Corporations and Other Business Enterprises Guiding Principles on Business and Human Rights: Implementing the United Nations "Protect, Respect and Remedy" Framework, U.N. Doc. A/HRC/17/31, 21.03.2011 (hereinafter Guiding Principles).

${ }^{20}$ See Human Rights Council, Human rights and transnational corporations and other business enterprises, Resolution A/HRC/RES/17/4.

${ }^{21}$ See Guiding Principles, para 5.

${ }^{22}$ Id.
} 
As far as responsibility for human rights infringements is concerned, the Guiding Principles aim to 'clearly differentiate the respective roles of businesses and governments and make sure that they both play those roles'. ${ }^{23}$ In other words, according to the Guiding Principles while governments retain the exclusive responsibility for protecting and fulfilling human rights obligations, the litmus test for corporations under the Guiding Principles only inquires whether business enterprises respect human rights. Indeed, the Guiding Principles are intended to elaborate on the implications of existing standards and practices for States and businesses, rather than create new international law obligations. As with the Framework, they represent 'soft' rather than 'hard' law (but with the possibility, as with any such instrument, they may evolve over time into hard law or otherwise inform standards of care). The Principles track the structure of the Framework, with each substantive section addressed to one of the three pillars; accordingly as far as the first Pillar, the Principles reiterate the State's core duty to protect human rights (Principle 1), recommending, inter alia, that States should address any gaps in laws and policies requiring businesses to respect human rights, provide guidance to businesses on how to respect human rights, and encourage or require reporting by businesses on their human rights performance (Principle 3), exercise adequate oversight with respect to contractual relationships and ensure respect for human rights by State-controlled enterprises (Principles 4-6), promoting human rights through multilateral institutions dealing with business-related issues (Principle 10), etc.

As far as the second Pillar, the Principles calls on business enterprises to respect human rights. In particular, businesses must avoid infringing on human rights and address adverse human rights impacts with which they are involved (Principle 11). To do so, businesses should adopt a clear human rights policy statement approved at the most senior levels and embedded in the organization through operational procedures (Principles 15-16) and most important, conduct on-going human rights 'due diligence' process to identify, prevent, mitigate and account for how they address their impacts on human rights (Principles 17-21), engage in remediation where they have caused or contributed to adverse human rights impacts (Principle 22), explore ways to respect human rights regardless of the domestic enforcement context (Principle 23b); and treat the risk of contributing to gross human rights abuses through human rights violations as a matter of legal compliance wherever they operate (Principle 23c).

As far as the third Pillar, the Principles call for effective State-based and nonState-based remedial mechanisms for those affected by business-related human rights harms. In particular States should ensure access to State-based judicial and non-judicial grievance mechanisms and facilitate access to non-State-based grievance mechanisms (Principles 25-28); Businesses should establish or participate in non-State-based, operational-level grievance mechanisms to identify, track, and address adverse human rights impacts from their activities (Principle 29).

${ }^{23} \mathrm{Id}$. 
Grievance mechanisms should be legitimate, accessible, predictable, equitable, transparent, rights-compatible, a source of continuous learning, and-in the case of operational-level mechanisms-based on dialogue and engagement (Principle 31).

From a substantial point of view, Guiding Principles also include the corporate duty to respect human rights of persons with disabilities in the employment sphere. Indeed, principle 12 acknowledges that ' $[t]$ he responsibility of business enterprises to respect human rights refers to internationally recognized human rights - understood, at a minimum, as those expressed in the International Bill of Human Rights and the principles concerning fundamental rights set out in the International Labour Organization's Declaration on Fundamental Principles and Rights at Work'. The Commentary to Principle 12 goes further, admitting that, depending on circumstances, business enterprises may need to consider additional standards and, as for instance, enterprises should respect the human rights of individuals belonging to specific groups or populations that require particular attention, where they may have adverse human rights impacts on them. This include United Nations instruments that have elaborated further on the rights of indigenous peoples, women, national or ethnic, religious and linguistic minorities, children, as well as persons with disabilities.

\section{The Legal Enforcement of the Corporate Duty to Respect the Right to Employment of Persons with Disabilities}

From this last perspective, compliance with the legislation in force is a main requirement for all the companies, moreover when they pretend to be defined as socially responsible. In the area of employment of persons with disabilities, this means mainly three things: in the first place, compliance with existing national legislation on employment quotas for persons with disabilities, where this legislation exists; in the second place, compliance with equal treatment legislation which forbids all discrimination on grounds of disability among others; and, in the third place, the setting forth of reasonable accommodations to ensure persons with disabilities the enjoyment on equal basis with others of all human rights and fundamental freedoms. As a result of the European Directive 2000/78/EC on equal treatment in the workplace, ${ }^{24}$ and of the entry into force of CRPD, enacting

\footnotetext{
${ }^{24}$ The Directive 2000/78/EC establishing a general framework for equal treatment in employment and occupation (Employment Equality Directive), sets out broad equality and non-discrimination objectives - specifically including disability — in the field of employment and, crucially, calls on Member States to 'put into effect' the principle of equal treatment. The Directive requires Member States to prohibit, inter alia, discrimination on the grounds of disability in the fields of employment, occupation and vocational training. According to the directive, Member States are required to prohibit direct discrimination, indirect discrimination, harassment, victimisation and instructions to discriminate on the grounds, inter alia, of disability.
} 
such type of legislation is binding for all member States and, in effect, it has been enforced in the majority of the European countries. Most countries have legislation on the percentage of positions in the public-sector for persons with disabilities, and some also have quotas for the private sector, providing for sanctions for non-compliance. ${ }^{25}$ Through quota systems States establish an obligation for employers with more than a certain number of workers to employ a minimum percentage of people with disabilities (the range of quotas is normally between 2 and $5 \%$ ). Existing quota systems can be divided into two main categories: strict quotas and flexible quotas. Strict quotas refer to schemes in which a person with a disability is treated preferentially irrespective of whether he or she is as qualified as other applicants. With flexible quotas, an applicant with a disability is treated preferentially only if he or she has equal merits and qualifications as another applicant. States are facing challenges in establishing effective positive measures that adequately advance equal possibilities for persons with disabilities to participate in working life. In some countries quota obligation can be met by corporate actors through alternative options, which might include the payment of a compensation fee to a special fund for the employment of people with disabilities or the purchase of products and/or services from special companies (sheltered workshops) whose workforce is mainly composed of people with disabilities. As far as equal treatment legislation is concerned, such legislation prohibits all kind of direct or indirect discrimination on grounds of a person's disability in any of the stages of the labour market integration process (search, selection, hiring, professional promotion...). The obligation of equal treatment includes carrying out the necessary reasonable adjustments required by a person with disability to participate in any work activity on the same terms as all other employees. The legislation also includes the specific prohibition of harassment at work on grounds of disability and of discriminatory instructions, which means for instance that a company cannot ask a human resources company or temporary work agency to exclude people with disabilities from its recruitment processes. Finally, as far as the reasonable

\footnotetext{
${ }^{25}$ In Italy the Law 68/99 obliges both public and private employers with at least 15 workers, to hire disabled workers in accordance with reserve quota (art. 3). This mandatory hiring, limited to new workers and valid for technical/executive staff only, also concerns political parties, trade unions and no-profit associations operating in the field of social solidarity, assistance and rehabilitation. For police services, civil protection and national defence, the placement of persons with disabilities only concerns administrative services. Germany was among the first countries to adopt a quota-levy scheme in 1974. Under the Social Code, Book 9, of 2002, public and private employers with a workforce of at least 20 employees are required to ensure that $5 \%$ of their workforce is made up of people with disabilities. Employers who do not meet their quota obligation are obliged to pay a fixed compensatory levy for every unfilled quota place. In France, the funds arising from non-fulfilment of the quota obligation may be used to fund vocational training of individuals with disabilities. The French quota law also provides other options for employers to partially meet their obligation under the law, such as by purchasing goods or services from sheltered workshops employing disabled people, or by implementing an agreement, negotiated between employers' and employee associations, aimed at the integration of disabled workers, though recruitment, training, job retention or adjustment to technological change.
} 
accommodation principles is concerned, the provision of a reasonable accommodation by the employer is an individualized measure that does not need to be temporary in nature: in fact, it should be provided for an individual for the duration of his or her employment. Reasonable accommodation measures should be distinguished from affirmative action measures aimed at the favourable treatment of groups. Also, the duty to provide a reasonable accommodation should not be confused with the duty to comply with general accessibility and occupational health and safety standards. According to this duty, recognized both by Article 27 of the CRPD and Article 5 of the 2000/78/EC Directive, employers are required, in certain cases, to take appropriate measures to enable persons with disabilities to have access to, participate in, or advance in employment, or to undergo training, unless such measures would impose a disproportionate burden on the employer. In order to enforce this obligation disabled workers or job applicants claiming a reasonable accommodation should demonstrate that: they are (otherwise) qualified for the job; and the employer (or other party) was aware of their needs; and with an accommodation, they could (safely) perform the essential functions of that particular job. Employers are only exempted from this obligation in cases where they can prove that they were not aware of the need for an individual accommodation, or an effective accommodation, enabling the disabled worker/job applicant to perform the essential functions of a job, is not available, or the requested accommodation imposes a 'disproportionate burden' on the employer.

The disproportionate burden 'defence' for not accommodating a disabled person needs to be drafted carefully. Otherwise, unscrupulous employers might make recourse to this defence in order to avoid any obligation. Much litigation might ensue. The fact that the workplace or work schedule would be inconvenienced clearly does not amount to a 'disproportionate burden'. In practice, the question as to what constitutes a disproportionate burden very much depends on the context of the case concerned, and is not merely dependent on the financial costs of an accommodation or financial compensation schemes. It depends on such factors as its practical implications, effects on the overall work process, number of disabled workers already employed and length of the envisaged employment contract.

\section{Operationalizing Corporate Due Diligence Principle as to the Right to Employment of Persons with Disabilities}

If amongst corporate responsibilities in the field of the employment of persons with disabilities there is the duty to enforce legal norms on quotas, on reasonable accommodation, on non-discrimination, applicable to such category of workers, the question raises on how private entities should enforce these corporate obligations. The 2011 UN Guiding Principles, and the abovementioned evolution of international standards on corporate responsibility, have demonstrated that avenues 
for enforcing such corporate responsibilities should be found in the corporate due diligence duty.

The due diligence concept is an important development as it offers a general principle of corporate action that can form the basis of corporate obligations to act in a socially responsible manner. In particular this concept may lead to the development of corporate duties of care where due diligence is inadequately carried out and consequential loss is suffered by third persons whose interests are thereby harmed. Guiding Principles 17-21, discussing the practical steps that business enterprises should take to discharge this responsibility, appear under the heading 'Human rights due diligence'. These steps include having a human rights policy; assessing human rights impacts of business activities; integrating those values and findings into corporate cultures and management systems; and tracking as well as reporting performance. Also, the notion of due diligence is defined by the UN as follows: such a measure of prudence, activity, or assiduity, as is properly to be expected from, and ordinarily exercised by, a reasonable and prudent [person or enterprise] under the particular circumstances; not measured by any absolute standard, but depending on the relative facts of the special case. In the context of the Guiding Principles, human rights due diligence comprises an on-going management process that a reasonable and prudent enterprise needs to undertake, in light of its circumstances (including sector operating context, size and similar factors) to meet its responsibility to respect human rights. ${ }^{26}$

Furthermore, extremely interesting is the circumstance that such a duty appears to be complementary of the international human rights legal obligation of due diligence in relation to the actions of non-state actors, ${ }^{27}$ and the general voluntary business practice of due diligence. ${ }^{28}$

From this last perspective, the notion of due diligence in corporate governance environment, indeed, has emerged since long, across many industries and business activities such as mergers and acquisitions (M\&A), initial public offering (IPO), real estate, technology, human resources, supplier evaluation or private banking customer identification. In this field area due diligence (also known as due care) is essentially understood as a way of preventing damage or unnecessary harm to either party involved in a transaction or business decision. Failure to make this effort is considered negligence fault. In a financial transaction (M\&A, IPO) context, therefore, activating due diligence processes means carrying out an investigation or audit of a potential investment serving as a confirmation of all material facts in regard to a transaction. Hence, due diligence is a review of financial records including anything deemed material to the transaction, sell- or buy-side (financial capacity, honesty, reputation, management quality, ownership, etc.). Risk can materialize at various levels, e.g. via direct cost increase, revenue decrease, unmet expectations related to market access and growth, as swell as damaged brand value and reputation.

\footnotetext{
${ }^{26}$ UN Human Rights Office of the High Commissioner (2012).

${ }^{27}$ The leading case in this area is Velasquez Rodriguez v. Honduras, (1989 28 ILM 294).

${ }^{28}$ See, e.g., Perry and Herd (2004).
} 
Moreover, materialized risk at one level may impact at the other levels as well through cascading effects. For example, damaged brand value may reduce market access, leading to revenue decrease etc. A due diligence analysis, therefore, aims at identifying intangible factors responsible for undetected, and therefore unmanaged, risks leading to a common decision base in multi-actor situations facing intangibles and complexity. ${ }^{29}$ Just from this perspective, the SRSG has noted how '[b]usinesses routinely employ due diligence to assess exposure to risks beyond their control and develop mitigation strategies for them, such as changes in government policy, shifts in consumer preferences, and even weather patterns. Controllable or not, human rights challenges arising from the business context, its impacts and its relationships, can pose material risks to the company and its stakeholders, and generate outright abuses that may be linked to the company in perception or reality. Therefore, they merit a similar level of due diligence as any other risk'. ${ }^{30}$

If companies are to carry out due diligence, what is its scope? The process inevitably will be inductive and fact-based, but the principles guiding it can be summarized succinctly. The key goal of the procedure is to identify the materiality in risk areas, which usually are seen as merely intangible. The task is how to identify, measure and describe environmental and social performance of industrial activities in an aggregated form. The outcome should not only give specific risk information, it should also enable intra-organization benchmarking and management system development of corporate responsibility. The gained information and drawn conclusions then serve to take decisions on: whether or not engaging into a business transaction due to the level of identified new facts or potentially impacting effects which costs are or would be acceptable or inacceptable; what will be the resources needed for risk mitigation, i.e. to reduce economic impacts to an acceptable risk level; and what will be the costs of maintenance for the necessary and targeted quality of risk management. The described methodology involves three distinct phases: (1) a pre-investigation about the relevance of social or environmental topics in the given situation; (2) if the indication of relevance is strong enough, an initial screening is carried out; (3) followed by in depth investigation. Finally, as an option: follow-up of risk management activities.

Tasks to be performed within these three main phases may be summarized as follows. The first phase involves the screening of the business landscape of the sector in question for relevant and significant social risk areas. The relevance explains the level of potential risks a company has to face due to the type of sector it is in (like supply chain for toys manufacturing). The significance results from the analysis of the client's value chain: where and how strong might a potentially relevant issue impact the economic success factors. This first phase aims at giving a clear picture for the management whether or not there is a need for immediate action (e.g. immediate withdrawal from the deal) or for further investigation. Equally important is the ability of the company to have an independent external

\footnotetext{
${ }^{29}$ See Gorman et al. (2005).

${ }^{30}$ SRSG Report to UN Human Rights Council UN Doc. A/HRC/11/13 (April 22, 2009).
} 
view which allows to investigate for example critique from NGOs or other stakeholders like customers, joint venture partners, law enforcement bodies or investors. The second phase includes an in-depth investigation of critical issues and business activities for detailed risk assessment in a particular area of its value chain: supply, manufacturing, distribution, use and follow-on responsibilities like 'take-back' obligations. Based on the results from the first phase, on-site audits are carried out wherever necessary to enable a fact-based analysis of perceived risks and, if the case allows it, a fact-based stakeholder dialogue is performed. This gives the possibility to immediately investigate options to mitigate the risks: de-selection of suppliers, contractual obligations and review processes, direct management influence or even labelling of CSR-quality by a third-party. By providing the issue landscape and the economic implications mapping the method allows to deal with CSR-topics in the usually most pressing, financially relevant and by all management levels hopefully accepted way. It is the development from issuemanagement to integrated sustainability management at all levels of corporate responsibility: the board, the top-management, the value chain management, the specialist functions and the personnel in general. Finally, the third phase includes management activities performed to cope with evaluating the performance of singular remediation action, surveying the implementation steps of management quality improvements and assessing whether or not, for example, management information systems (MIS) follow also in economic terms the different anchoring procedures.

It follows that due diligence may be approached as a container concept. Every professional will first think of due diligence in his own field of expertise, depending on the scope and purpose of the project or of the corporate policy decisions which experts will be engaged for the due diligence process. For a full due diligence investigation, many different experts can be involved. Multidisciplinary teams will work on: business issues (this work will typically be performed by commercial lawyers and the company's commercial staff); financial position and forecast (the company's financial staff, investment bankers, accountants); technical aspects (in-house and external technical experts); tax risks (tax lawyers); corporate structure and legal liabilities (lawyers and notaries); real estate (notaries; real estate agents' valuation experts); pension issues (lawyers, tax lawyers, accountants and actuaries); IT issues (IT consultants); environmental issues (environmental law and administrative law specialists, technical environmental consultants); insurance issues (insurance or actuarial experts); and fraud and corruption (forensic accountants).

The abovementioned analysis demonstrates, also, how the perspective of due diligence is very much one of risk management, with the twist that the harm may occur outside the company, but then rebound to it in terms of reputational loss. The major advantage of human rights due diligence is that its outcomes can be fed into the existing system of corporate risk control. It becomes, in sum, embedded, rather than an 'add on' that can be quickly put to one side. However, as it has been argued 'the human rights due diligence assessment may not sit easily with the corporate aim of profit maximization' particularly since the basis of corporate law remains 
'rooted in the prioritization of enhancing shareholder value"31 or as noted in the literature 'some key ways of placing rights related elements on the corporate radar (e.g. socio-ethical risk assessment) involve mind-sets and skills that are still nonconventional in many board rooms'. ${ }^{32}$

In addition, and with specific regard to the employment of person with disabilities issue, due diligence in relation to labour rights remains quite a blunt instrument that has not fully thought through what it means in relation to the enterprise's own workers or workers of enterprises linked to it in the supply chains, as contrasted to other individuals, groups or communities affected by their operations. Workers are not 'stakeholders' in the same way as persons or groups external to the enterprise's production of value added. It will therefore be very important to see how due diligence processes will be carried out in relation to employment of persons with disabilities. Due diligence processes in such situations need to take into account the structure of firms and their business relationships, the information relied upon, and the broader culture within an enterprise. As a general matter, the Guide for integrating Human Rights into Business Management, developed by BLIHR, the Office of the UN High Commissioner for Human Rights and the UN Global Compact, sets out a series of processes for situating human rights considerations within standard business practices, from strategy to measuring impact and auditing and reporting. ${ }^{33}$ The due diligence process itself identifies the steps to be taken in carrying it out. However, other factors will need to be taken into account. One is better identification along the supply chain as well as in the company of who is responsible for what. Another step would be setting out some criteria for assessing the reliability of information relied upon and the transparency about its sources. When businesses carry out due diligence in relation to other types of risks, they rely on internal and external sources. In the now more regulated financial services sector, due diligence is reported as being regularly undertaken in relation to prospective clients, prospective employees and prospective investors. Information comes from public and private sources, and pose the challenges of verification, timeliness, multiplicity of sources, and cost, particularly from commercial databases. $^{34}$ The commentary to Principle 21 suggests that business reporting should include 'indicators concerning how enterprises identify and address adverse impacts on human rights'. The most likely scenario is that they will seek out existing indicators. Here we find a number of competing sources, of variable quality and accessibility of data. Multiple, non-transparent and non-comparable firm-based indicators would not be particularly helpful. But more importantly, there is always the risk of reductionism, that the indicator becomes not a proxy for the right, but a reduced notion of the right itself. Context and nuances that can be critical in the

\footnotetext{
${ }^{31}$ See Muchlinski (2012), p. 177.

${ }^{32}$ See Horrigan (2010), p. 330.

${ }^{33}$ The Guide may be accessed at the following website: http://www.integrating-humanrights.org/ about_all_steps.

${ }^{34}$ Ainsworth (2007), pp. 250-251.
} 
enjoyment of human rights in the context of labour risk being lost through an overreliance on indicators. Last but certainly not least, the overall environment in which human rights due diligence is carried out also matters. Muchlinski has warned, 'unless a corporate culture of concern for human rights in instilled into the officers, agents and employees of the company, due diligence could end up missing the very issues it is set up to discover. At worst it could degenerate into a 'tick-box' exercise designed for public relations purposes rather than a serious integral part of corporate decision-making. It is here that the ethical duty to respect human rights is key. The acceptance of such a duty may be said to 'constitutionalise' concern over human rights impacts in the corporate psyche and culture. The due diligence process then allows this concern to be put into operation'. ${ }^{35}$

Finally, even if the Guiding Principles are only recommendatory and even if due diligence is a voluntary process, the application of due diligence approach in these situations may be used as a shield against legal actions. In effect, notwithstanding the fact that the 2011 Guiding Principles contain the caveat that 'nothing in these Guiding Principles should be read as creating new international law obligations...., at the same time, a concern about possible legal consequences relating to non-respect for human rights, surfaces from time to time in the SRSG's reports and are certainly on firms' radar screens. Principle 23, indeed, in the context of remediation, recognizes that in all contexts, business enterprises should 'treat the risk of causing or contributing to gross human rights abuses as a legal compliance issues wherever they operate'. Furthermore, the commentary to Principle 17 closes with this remark: 'Conducting appropriate human rights due diligence should help business enterprises address the risk of legal claims against them by showing that they took every reasonable step to avoid involvement with an alleged human rights abuse. However, business enterprises conducting such due diligence should not assume that, by itself, this will automatically and fully absolve them from liability for causing or contributing to human rights abuses'. With proper documentation, however, evidence of having engaged in human rights due diligence could certainly help a business entity make its case in some circumstances. Civil law offers far greater potential application of such due diligence scheme: Canada due diligence has already 'developed beyond a simple commercial risk assessment process into a basic element of complying with a wide range of environmental, health, safety and other regulations involving strict liability offences, becoming analogous to the 'reasonableness' element in civil tort cases' ${ }^{36}$ The same Special Representative in his 2010 interim report pointed to examples of national legislation from the Netherlands, Singapore and the United States that he saw as widening the responsibilities of directors when considering the duties owed to their firms. ${ }^{37}$

\footnotetext{
${ }^{35}$ Muchlinksi (2012), cit., p. 156.

${ }^{36}$ Muchlinksi (2012), cit., p. 157.

${ }^{37}$ SRSG, Corporate Law Project: Overarching Trends and Observations, p. 14.
} 


\section{Corporate Social Responsibility and Disability: Going Beyond Strict Legislation}

Both States and corporate employers are obligated by the CRPD and, as far as the EU level, by the 2000/78/EC Directive, to protect the right of people with disabilities to work. However, business sector may employ people with disabilities not only to fulfil legal and moral obligations, but also for economic reasons. Indeed, hiring persons with disabilities makes economic sense from several perspectives. In the first place, persons with disabilities are high quality and reliable employees: indeed many workers with disabilities have equal or higher performance ratings on the job than workers without disabilities. Secondly, many workers with disabilities have higher job retention than non-disabled workers. In the third place, persons with disabilities may have underutilized talents and perspectives that can assist in developing new products and broaden the consumer base of your company. From this side, they may bring abilities to a position due to the affect of their disability, for instance an unusual degree of creativity, high level of accuracy, or attention to detail. In the fourth place, persons with disabilities may enhance corporate business culture, employee morality and business reputation: in these situations indeed, nondisabled employees may feel more positively about their company and its contribution to their community; corporate managerial staff may come to feel that they are better able to learn the needs of their staff and to improve their communication with the general workforce. Finally, most reasonable accommodations do not carry any significant cost, and non-disabled employees commonly require accommodations. Accommodations that involve physical modifications also benefit consumers and non-disabled employees by creating a universally friendly environment. For example, a ramp that benefits a wheelchair-using employee also benefits customers with prams and non-disabled employees who transport inventory. There are 'ripple effects' that emanate from reasonable accommodations. These include higher productivity, greater dedication, and more widespread use by workers without disabilities of efficiency-enhancing technologies previously used only by their peers with disabilities.

Upholding legal and moral responsibilities so that people with disabilities can claim their right to work is an important step in fighting against stereotypes falsehood. A significant cultural myth is the idea that people with disabilities are unable to be effective workers. By employing a person with a disability corporate actors may help to erode prejudices and misconceptions regarding this group. Employment is a hallmark of true citizenship for it enables individuals to participate meaningfully in society. The workplace is where meaningful conversations occur, where meaningful relationships form, and where loyalty to co-workers is forged. Being a part of this community is a crucial way for people with disabilities to be full members of society, and to be deemed as such. Probably the best example of the fallaciousness of this stereotype is represented by those corporate best practices concerning the access to employment of persons with autism spectrum disorder (ASD). Danish corporation Specialisterne, which is a socially innovative 
company where the majority of employees have a diagnosis on the ASD and work as business consultants on tasks such as software testing, programming and dataentry for the public and private sectors, is perhaps the most well known example. The Specialisterne model, where enterprises outsource some processes and also outsource the responsibility for ASD people working on these processes, although already in place since 2005 , is innovative. ${ }^{38}$ Pilot projects conducted by Specialisterne confirmed that this model could potentially work across the EU, other projects of Specialisterne are expected to demonstrate that they work worldwide. $^{39}$

Other examples of employment's integration of persons with autism involve the case of Passwerk, a Belgian software testing company, which has developed strategies to handle social and communication skills difficulties that employer with autism usually experience in the workplace. Passwerk provides training and job coaching for its employees with autisms not only in professional development, but also in social skills development, tailored to each employee's individual needs. In addition, when an employee is unable to carry out a particular task, due to the limitations of their autism, a 'job coach' will step in to assist. Passwerk has one job coach for every seven employees with autism. The job coaches work closely with the employees with autism, acting as a first point of contact for both employees and customers. As in most workplaces, each employee's skills are put to use in the most appropriate and efficient way possible, so that together the team gets the job done well.

In the United States, a small farming business called Green Bridge Growers is succeeding to grow produce all year-round, primarily using a method called 'aquaponics' where fish and vegetables grow in harmony. The company now employs a number of individuals with ASD and finds that the scheduling, precision and monitoring required in aquaponics perfectly match with their skills. Green Bridge Growers was founded to deal with a problem that highly intelligent adults with autism often face. Successful initiatives designed to employ people with autism may be found also at the level of large international companies willing to achieve social as well as business goals and create a more diverse workforce. In 2007, Walgreens, a chain of pharmacies in the United States, opened a new distribution centre where more than $40 \%$ of its staff has some disabilities, including autism. An on-site training facility helps those with special needs become prepared for the job and all employees, with and without disabilities, meet the same productivity goals. Walgreens aims to fill $10 \%$ of its distribution centre production jobs

\footnotetext{
${ }^{38}$ Other examples include software giant SAP, who recently announced plans to hire 650 new employees with autism, Auticon in Germany, and Apiritech and Semperical in the US, which have followed Specialisterne's example. These organizations structure workplace environments that enable individual value creation, or focusing training programs on bringing out and developing exceptional abilities, or establishing performance-management systems that de-emphasize conformity and instead focus on removing obstacles to higher performance.

${ }^{39}$ See European Commission, Results of four pilot projects on employment of persons with autism, vp/2010/017, p. 15.
} 
with people with disabilities, and is already more than halfway towards reaching this goal. Finally in Italy, cosmetic company L'Oréal has started a long-term project to facilitate the employment of people with autism throughout the company. The company has created training for employees with autism, other staff and managers and designated specific staff members to act as coaches for employees with autism. L'Oréal also has a policy to ensure they employ people with disabilities in at least $2 \%$ of positions within the company. ${ }^{40}$

In conclusion, companies which aim to be socially responsible on disability, should set themselves a series of objectives to pursue independently from the circumstance that the company is bound by quota legislation, or not. It should have to establish concrete employment targets for people with disabilities and an action plan to achieve these targets; it should have to employ persons with disabilities working at all company levels and to fix for this category of employees concrete targets facing additional challenges to being included in the labour market, like women with disabilities, people with more severe disabilities and elderly people with disabilities.

\section{Conclusions}

Human rights corporate responsibility goes beyond core company activities and donations to charity, and is understood as an integrated part of doing business, based on corporate values included in strategy and daily operations. Moreover, the current financial crisis has shown how business activities solely motivated by the desire for short-term profit can have serious global consequences, while in order to achieve sustainable practices, business need to be ethical and invest in local communities and economies. The importance to address disability as a part of CSR strategies is certainly becoming more visible in the practices of the MNEs and important part of successful CSR strategies and inclusive corporate culture. There is the need for more and more 'disability champions': business cases and best practices advocating strongly for hiring persons with disabilities Also, the importance of the issue is proved by the evolvement of special organizations and networks that aim to improve the underemployment of persons with disabilities and cooperate with enterprises (both public and private) in extending their CSR strategies.

This notwithstanding, 'disability' still remains a rather sensitive element of CSR for the companies and is addressed differently due to the different levels of understanding the importance and the benefits of such actions. The present analysis

\footnotetext{
${ }^{40}$ Aiming to integrate young adults in particular into their workforce, L'Oréal is working with Fondazione TEDA (an association for autism) to develop the project. Activities proposed to people with autism include administration tasks such as working with databases, updating files, data entry and archiving, as well as packaging cosmetics, quality checking, security and other tasks.
} 
demonstrates that it is not sufficient that corporate entities address disabilities in their organizational norms and values; they have to incorporate this issue further into corporate culture, HR policies and work environment setting forth a system of corporate governance which take into account these concerns. Indeed, it is definitely a challenge for an enterprise not only to demonstrate attitude towards inclusion of persons with disabilities in CSR strategies, but to promote the implementation of these policies further into 'inclusive corporate culture and work environment'. Thus, to make the choice work, creative and diverse options are needed as not one solution does fit for all. Besides, dissemination of the positive examples for the larger number of companies to understand the benefits of engaging in such activities, is highly important.

Open Access This chapter is distributed under the terms of the Creative Commons Attribution Noncommercial License, which permits any noncommercial use, distribution, and reproduction in any medium, provided the original author(s) and source are credited.

\section{References}

Ainsworth M (2007) Complete compliance: due diligence on companies and individuals. Bus Inf Rev 24(4):250-251

Alston P, Steiner HJ (2000) International human rights in context, 2nd edn. Oxford University Press, Oxford/New York, pp 180-185

Bickenbach JE (1999) Models of disablement, universalism and the international classification of impairments, disabilities and handicaps. Soc Sci Med 48(9):1173-1187

Clapham A (2006) Human rights obligations of non-state actors. Oxford University Press, Oxford, pp 347-436

Cushman T (ed) (2012) Handbook of human rights. Routledge, London

Eide A (1984) The international human rights system. In: Eide A et al (eds) Food as a human rights. United Nations Publisher, Tokyo, pp 152-161

French S (1994) What is disability? In: French S (ed) On equal terms. Working with disabled people. Butterworth-Heinemann, Oxford, pp $4 \mathrm{ff}$

Gorman GG, Rosa PJ, Faseruk A (2005) Institutional lending to knowledge-based businesses. J Bus Venturing 20:793-819

Grammenos S (2011) Indicators of disability equality in Europe. ANED 2011 Task 4. www. disability-europe.net/content/aned/media/ANED\%202011\%20Task\%204\%20-\%20Synthesis $\% 20$ Report.doc. Accessed 30 Oct 2014

Horrigan B (2010) corporate social responsibility in the 21st century: debates, models and practices across government, law and business. Edward Elgar Publishing, Cheltenham

Hunt L (2007) Inventing human rights. A history. Norton, New York

Ishay M (2008) The history of human rights: from ancient times to the globalization era. University of California Press, Berkeley

Muchlinski P (2012) Implementing the new UN corporate human rights framework: implications for corporate law, governance and regulation. Bus Ethic Q 22(1):145-177

Oliver M (1996) Understanding disability: from theory to practice. Macmillan, Hampshire

Perry JS, Herd TJ (2004) Mergers and acquisitions: reducing M\&A risk through improved due diligence. Strategy Leadersh 32(2):12-19 
Quinn G (1999) The human rights of people with disabilities under EU law. In: Alston P, Bustelo M, Heenan J (eds) The EU and human rights. Oxford University Press, Oxford, pp $281 \mathrm{ff}$

Rasche A, Kell G (eds) (2010) The United Nations global compact: achievements, trends and challenges. Cambridge University Press, Cambridge

Rehman J (2010) International human rights law. Pearson, Harlow

Shakespeare T (2006) Disability rights and wrongs. Routledge, Abingdon

Udombana N (2004) Between promise and performance: revisiting states' obligations under the African Human Rights Charter. Stanford J Int Law 40:105-142

UN Human Rights Office of the High Commissioner (2012) The corporate responsibility to respect human rights: an interpretive guide. United Nations, Geneva, p 4

van Hoof GJH (1984) The legal nature of economic, social and cultural rights: a rebuttal of some traditional views. In: Alston P, Tomaševski K (eds) The right to food. Martinus Nijhoff Publishers, The Hague, pp 97-110

Marco Fasciglione is Researcher at the Institute for International Legal Studies (ISGI-CNR), Naples. 